\title{
Stability analysis and evaluation of a landslide area in Sichuan
}

\author{
Bingbing Chen ${ }^{1 *}$, Zhenhua $\mathrm{Fu}^{2}$, Tao $\mathrm{Chen}^{3}$ \\ ${ }^{1}$ College of Construction and Engineering, Jilin University, Changchun 130026, China \\ ${ }^{2}$ College of Environment and Civil Engineering, Chengdu University of Technology, ChengDu \\ 610000, China \\ ${ }^{3}$ The 137 Geological Party, Coalfield Geology Bureau of Sichuan Provence, Dazhou 635000,
} China

Email: cbb.315@163.com

\begin{abstract}
Located on the northern bank of the Jinsha River, the Guanlinping landslide area of Longping Village, Xin'an Town in southwestern Pinshan County poses a great threat to the life and property of the local residents. In this paper, the stability of the landslide area is qualitatively and quantitatively analyzed through the examination of the engineering geological conditions and the influencing factors of stability.
\end{abstract}

Keywords: Landslide, Landslide Geological Conditions, Stability Analysis and Evaluation.

\section{INTRODUCTION}

Pingshan is a county in Yibin Prefecture, Sichuan Province. It is situated on the southern fringe of Sichuan Province, at the western end of Yibin Prefecture, and on the northern bank of Jinsha River. The county has a rugged terrain dotted with undulating hills, narrow valleys and steep slopes. The outcropping stratums are complicated and diverse, as evidenced by the complicated structures, developed faults and broken rocks. The geological environment is relatively fragile as geological disasters occur frequently under rainstorm and human engineering activities.

In 2008, the initial sliding movement took place in Guanlinping landslide area of Longping Village, Xin'an Town. During the heavy rain in July 2013, new deformation appeared, resulting in obvious signs of deformation. The landslide area poses an ever-increasing threat to the life and property of the local residents. Therefore, it is necessary to carry out stability analysis of this landslide area.

\section{ENGINEERING GEOLOGICAL CONDITIONS}

\subsection{Topography}

The landslide area lies in the transitional zone from the Yunnan-Guizhou Plateau to the Sichuan Basin, which belongs to the middle and low hilly terrain. The mountains extend roughly along the tectonic lines in the near S-N direction and W-NW direction. The geomorphic development is dominated by tectonically eroded oblique deep hills and low mountains. Overall, the terrain is high in the south, east and west and low in the north and middle, featuring overlapping mountains and crisscrossing valleys.

Except for a few sections, the Jinsha River valley mostly flows through $80-300 \mathrm{~m}$ wide narrow "U" or "V" shaped valleys. The river slopes are normally $20^{\circ}-30^{\circ}$, the tallest of which exceeds $600 \mathrm{~m}$ in height. The feet of the slopes are often covered by various quantities of colluvial deposits. Alluvial or diluvial fans are commonplace at the outlets of tributaries and gullies. The terraces are well developed and clearly arranged on both banks. Classes I V terraces are observed in Dashaba, Suijiang, Shilong and Longdong. The height of each layer of terrace is about $20 \sim 60 \mathrm{~m}$.

\subsection{Stratigraphic lithology}

The surface of the survey area is widely covered by various deposits, mainly Quaternary colluvial deposits (Q4dl+col) and landslide deposits (Q4del); the bedrock is exposed only in the front and rear of the landslide area; the underlying bedrock in the survey area is predominantly made of the Upper Triassic Xujiahe Formation (T3xj) sandstones.

(I) Quaternary landslide accumulation layer (Q4del):

The surface is composed of yellowish gray and dark gray gravelly soils and block stones. The soil layer is thicker in the rear section $(5 \sim 6 \mathrm{~m})$ than the middle and front sections $(2 \sim 3 \mathrm{~m})$ of the landslide area. The rear section has many farmlands.

(II) Quaternary colluvial accumulation layer (Q4dl+col):

Distributed at the foot of high slopes in the middle and rear sections of the landslide area, the $5 \sim 7 \mathrm{~m}$ thick layer mainly consists of argillaceous sandstone fragments and block stones.

(III) Xujiahe Formation (T3xj)

This formation is an interbed of yellowish gray sandstones 
and dark gray shales. The shales are thin-layered, featuring broken and easily weathered outcrops and fragmented surfaces. The sandstones, however, are medium-thick layered (thick-layered in some areas) and vertically fissured, accompanied with complete outcrops. In the rear section of the landslide area, the strike and dip of the outcropping bedrock of the slope is $275^{\circ} \angle 9^{\circ}$. A set of steeply inclined structural planes are developed with the strike and dip of $\mathrm{N} 15 \sim 20^{\circ} \mathrm{W} /$ near vertical $\left(\mathrm{NE} \angle 80^{\circ}\right)$. The structural planes are straight and not open. On the opposite slope, the strike and dip of the outcropping bedrock is $284^{\circ} \angle 12^{\circ}$. A set of steeply inclined structural planes are developed with the strike and dip of $155^{\circ} \angle 65 \sim 75^{\circ}$. The structural planes are straight and not open. The bedrock is mainly distributed in the slope across the gully before the landslide area and the rear wall of the landslide area.

\subsection{Geologic structure}

The geological structure in the area is mainly folds. The tectonic structure is not well developed. The tectonic form is dominated by the NE-trending tectonic structure, followed by the NW-trending tectonic structure. The NE-trending fold structure is mainly composed of Lingjiayan syncline, Wujiaobao-Loudong anticline, while the WE-trending fold structure is represented by Longqiao anticline.

The geological structure in landslide area and the surrounding areas is dominated by folds, and the tectonic structure is not well developed. The landslide area is located in the near-axis portion on the west wing of WuzhishanLongqiao anticline. The $7 \mathrm{~km}$ long anticlinal axis points to $315 \sim 350^{\circ}$. The NE wing is steep with a dip angle of $28 \sim 41^{\circ}$ and the SW wing is gentle with a dip angle of $18 \sim 31^{\circ}$. The stratigraphic composition is $\mathrm{J} 2 \mathrm{~s} \sim \mathrm{T} 1$. Longqiao anticline extends from NW to SW, which obliquely crossing the development direction of the Jinsha River. For the slip bed, the strike and dip is: $275^{\circ} \sim 284^{\circ} \angle 10^{\circ} \sim 13^{\circ}$. No large faults are found in the landslide area.

\subsection{Hydrogeologic conditions}

(I) Surface water

The landslide area boasts simple hydrogeological conditions without any exposure of surface water.

(II) Groundwater

Drilling and field investigation show that the slope survey area has simple hydrogeological conditions. For example, small catchment area, smooth surface drainage and poor water bearing conditions. According to the characteristics of water-bearing rock mass, the groundwater in the area are unconsolidated formation pore water and bedrock pore water/fissure water.

\section{LANDSLIDE CHARACTERISTICS}

\subsection{Basic characteristics and boundaries of the landslide area}

The landslide area covers around $60,912 \mathrm{~m}^{2}$. In the shape of a round-backed armchair, the area is about $216 \mathrm{~m}$ long longitudinally and $282 \mathrm{~m}$ wide laterally. The elevation of the low rear edge is $690 \mathrm{~m}$, and that of the tall front edge is $618 \mathrm{~m}$, putting the relative height difference at $72 \mathrm{~m}$. The average slope falls between 10 20. The strike and dip of the underlying stratum of the area is $275^{\circ} \angle 9^{\circ}$. The topsoil is about 3 6m thick on average. With a total earth volume of $24.36 \times 106 \mathrm{~m}^{3}$, the research object is a medium-sized thrust load-induced shallow soil landslide area (Figure 1).

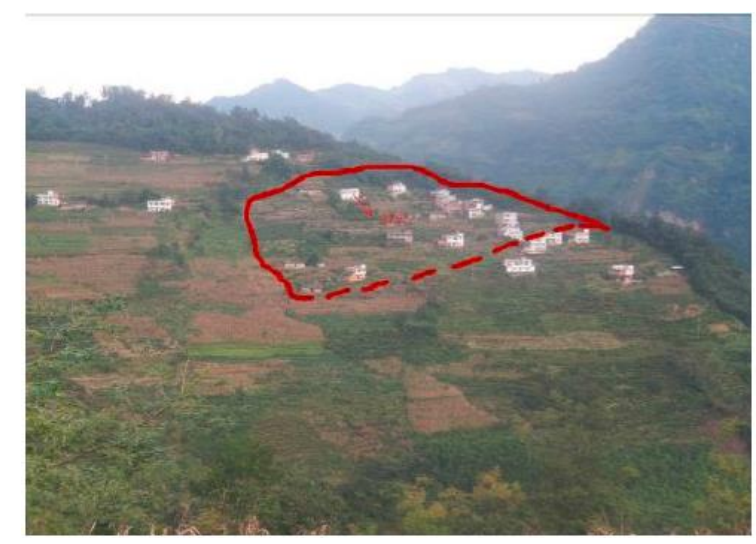

Figure 1. Panorama of the landslide

\subsection{Deformation characteristics}

The landslide area suffers from obvious deformations. Deformation failure is mainly demonstrated by ground cracking and subsidence, house tensile fracture, slope deformation and bulging deformation. The cracks in the landslide area concentrate in farmlands, buildings and courtyards (Figures 2 7). The rear edge of the landslide area is marked by a steep scarp near the southern ridge, where the bedrock is outcropped, the front edge is marked by the intersection of scattered scarps, the left edge is bounded by the lateral arc-shaped through cracks, and the right edge is bounded by the dividing line between steep and gentle landforms.

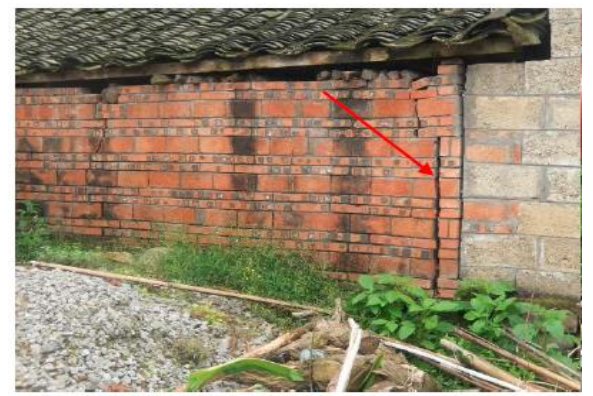

Figure 2. External wall cracking caused by rear edge tension cracks

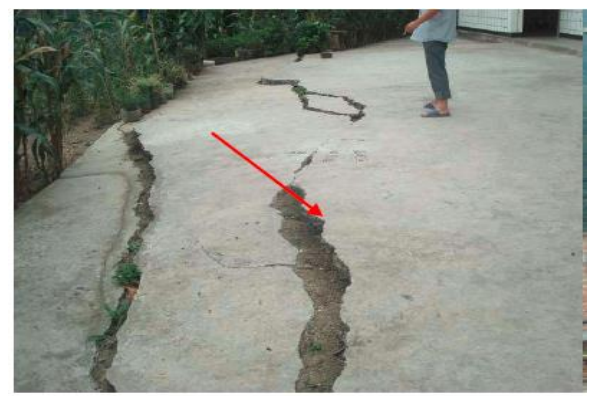

Figure 3. Courtyard settlement caused by rear edge tension cracks 


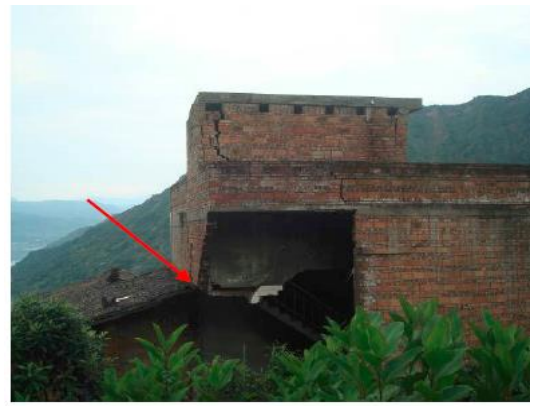

Figure 4. House damages caused by left edge shear cracks

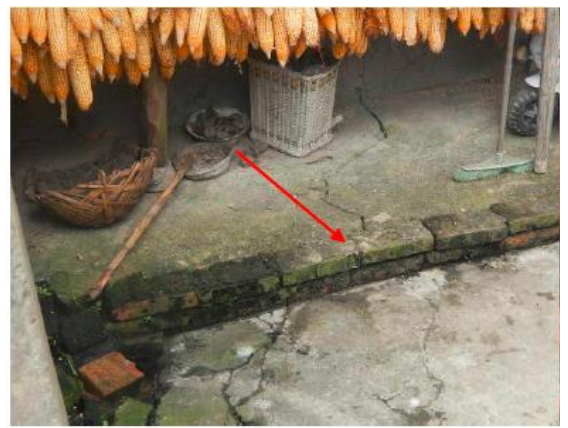

Figure 5. Courtyard cracking caused by left edge shear cracks

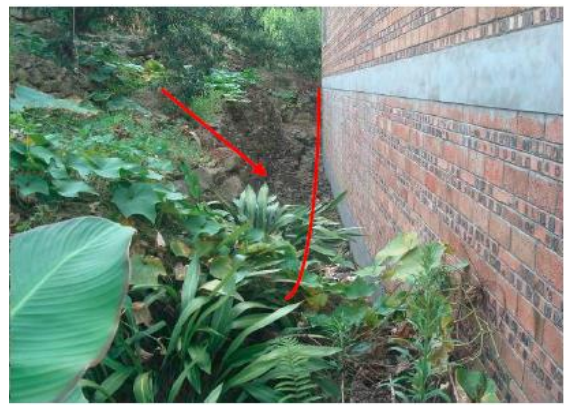

Figure 6. Retaining wall collapse caused by front edge bulging cracks

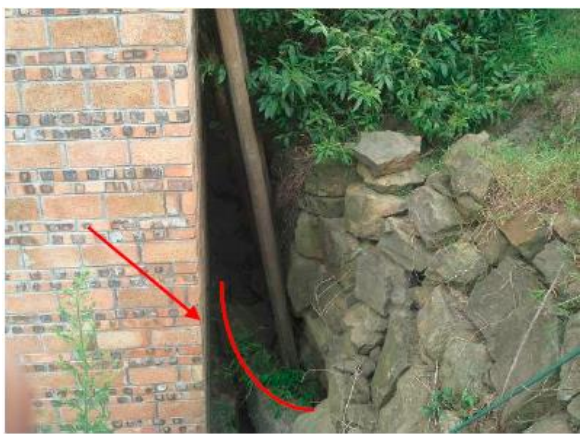

Figure 7. Drainage channel deformation caused by front edge bulging cracks

\section{STABILITY ANALYIS AND EVALUATION}

\subsection{Analysis landslide formation and mechanism}

This section is about the preliminary analysis of the existing deformation and failure phenomenon and mechanism of the landslide area. The influencing factors of landslide stability are divided into internal and external ones. The internal factors control the stability of the landslide area, while the external factors induce the destructive effect of the landslide.

(I) Internal factors

The main internal factors affecting landslide stability include landform and distribution and characteristics of rock and soil.

1. Landform

The elevation of the front edge is $618 \mathrm{~m}$, and that of the rear edge is $690 \mathrm{~m}$, putting the relative height difference of the slip mass at $72 \mathrm{~m}$. The slope of the landslide area falls between 10 and $20^{\circ}$. The front edge has a large freeing surface and an outward-leaning bedrock surface, providing favorable conditions for the sliding movement of the landslide area.

2. Distribution and characteristics of rock and soil

The landslide mass has a binary structure: the upper potential slip mass is Quaternary eluvial layer of silty clay and crushed stones, and the lower potential slide bed is Upper Triassic Xujiahe Formation sandstones and shales. The layer of silty clay and crushed stones is highly water permeable and easy to get saturated, while shales have poor permeability. Thus, the bedrock surface becomes an active band of groundwater, making it easy to form a high pore water pressure on the bedrock surface. What is worse, the long-term groundwater action reduces the shear strength of the soil near the bedrock surface, turning the bedrock surface into a potential slip mass and endangering the stability of the landslide area.

(II) External factors

External factors are mainly house construction loads and rainfall on the rear edge.

1. Rainfall

The main deformation of the landslide area is directly related to rainfall. Due to the large catchment in the area, the surface water pours into the landslide mass. The injection hinders the slope drainage, saturates and softens the soil mass. Under the long-term action of groundwater, the landslide area is subjected to a decline of shear strength and eventually transformed to a slip surface. In the meantime, the watersaturated slip zone soil adds to the weight of the slope, and groundwater creates pore water pressure inside the slope. Both of the actions weaken the sliding resistance and increase the sliding force of the rock and soil on the inclined slope, thus reducing the stability of the landslide area. As a consequence, the soil mass and buildings on the slope will be deformed ultimately, and the slope will be hit by landslide.

2. Building construction load on the rear edge

Since 2008, more than 20 households have moved into the landslide area. Most of them built 2-3 story brick and concrete houses in the middle section and on the left side of the rear edge of the landslide area (the bearing stratum of the house foundations is composed of gravelly soil and block stones). The construction results in concentrated loads on the back edge of the landslide area. Coupled with the softening effect of heavy rains and the large freeing surface of the front edge, the building construction load will ultimately lead to slope instability.

\subsection{Landslide stability evaluation}

\subsubsection{Qualitative evaluation}

According to field observation and survey, the upper part of the landslide area is unloaded and relaxed. The conditions 
facilitate the infiltration of rainwater into the slope. After heavy rains, the soil mass is gradually saturated and the slope strength is reduced, causing soil mass slippage on the rear edge. The monitored data show that the landslide area is under rapid deformation. The formation is fast and severe. Thus, the landslide area is naturally unstable. In the case of heavy rain, the instability is exacerbated and the hazard is amplified.

\subsubsection{Quantitative evaluation}

In order to obtain the overall stability of the landslide area, the 1-1 ', 2-2', 3-3 ' longitudinal sections are selected for landslide stability checking and thrust calculation.

\subsubsection{Calculation model}

The soil landslide area has a polyline slip surface. According to the Specification of Geological Investigation for Landslide Stabilization, the landslide stability and thrust of the polyline slip surface should be calculated by the transmission coefficient method. The basic assumptions are as follows:

(1) Take $1 \mathrm{~m}$ wide slip band along the cross-sectional direction as the basic section of the calculation, excluding the friction on both sides;

(2) Each slip band of the landslide area is sliding as a whole;

(3) The direction of the thrust of the landslide mass is parallel to the sliding surface.

\subsubsection{Calculation method}

Stability formula:

$$
K_{f}=\frac{\sum_{i=1}^{n-1}\left\{\left\{\left\{W_{i}\left[\left(1-r_{u}\right) \cos \alpha_{i}-A \sin \alpha_{i}\right]-R_{D i}\right\} \tan \varphi_{i}+C_{i} L_{i}\right\} \prod_{j=1}^{n-1} \psi_{j}\right\}+R_{n}}{\sum_{i=1}^{n-1}\left\{\left[W_{i}\left(\sin \alpha_{i}+A \cos \alpha_{i}\right)+T_{D i}\right] \prod_{j=1}^{n-1} \psi_{j}\right\}+T_{n}}
$$

where $r_{u}=\frac{U V \times H V W}{T V \times S M V M}$

$U V:$ Underwater volume of landslide area

$T V$ : The total volume of the slip mass

$H V W$ : Hydrological volume weight

$S M V M$ : Slip mass volume weight

$R_{D i}=\gamma_{\omega} h_{i \omega} L_{i} \sin \beta_{i} \sin \left(\alpha_{i}-\beta_{i}\right)$

$\prod_{j=1}^{n-1} \psi_{j}=\psi_{i} \psi_{i+1} \ldots \psi_{n-1}$

$\psi_{i}=\cos \left(\alpha_{i}-\alpha_{i+1}\right)-\sin \left(\alpha_{i}-\alpha_{i+1}\right) \tan \varphi_{i+1}$

$R_{n}=\left\{W_{n}\left[\left(1-r_{u}\right) \cos \alpha_{n}-A \sin \alpha_{n}\right]-R_{D n}\right\} \tan \varphi_{n}+c_{n} 1_{n}$

$T_{D i}=\gamma_{\omega} h_{i \omega} L_{i} \sin \beta_{i} \cos \left(\alpha_{i}-\beta_{i}\right)$

$T_{n}=W_{n}\left(\sin \alpha_{n}+A \cos \alpha_{n}\right)+T_{D n}$

where: $K_{f}$ is the landslide stability coefficient; $W_{i}$ is the weight of the i-th slip band $(\mathrm{kN} / \mathrm{m}) ; r_{u}$ is the pore pressure ratio; $a_{i}$ is the slip surface dip angle of the i-th slip band $\left(^{\circ}\right) ; A$ is the horizontal seismic coefficient; $r_{w}$ is the volume weight of water $(\mathrm{kN} / \mathrm{m}) ; h_{i w}$ is the height from the slip band waterline to the slip surface (m); $L_{i}$ is the slip surface length of the i-th slip band $(\mathrm{m}) ; \beta_{i}$ is the average dip angle of the underground flow line of the i-th slip band $\left(^{\circ}\right) ; \varphi_{i}$ is the internal friction angle of the i-th slip band $\left(^{\circ}\right)$; ci is the cohesion of the i-th slip band $(\mathrm{kPa}) ; \psi_{i}$ is the transfer coefficient.

Landslide area thrust formula:

$P_{i}=P_{i-1} \times \psi+K_{s} \times T_{i}-R_{i}$

where $P_{i}$ and $P_{i-1}$ are the remaining sliding forces of the i-th and i+1-th slip bands, respectively; $K_{s}$ is the designed safety factor (its value is determined in light of the grade and condition of the landslide control project and in accordance with the Specification of Design and Construction of Landslide Stabilization); $T_{i}$ is the sliding force on the i-th slip band $(\mathrm{kN} / \mathrm{m}) ; R_{i}$ is the sliding resistance on the $\mathrm{i}$-th slip band $(\mathrm{kN} / \mathrm{m})$.

\subsubsection{Calculation conditions and parameter values}

I. Calculation conditions

In view of the features of landslide deposits and possible loads in the area, the calculation mainly considers dead load, heavy rain (saturated slope mass) and earthquake. Specifically, three conditions are specified for calculating the stability of each section of the landslide area and the remaining sliding force of each slip band.

Condition I: dead load (natural condition);

Condition II: dead load (heavy rain);

Condition III: dead load (natural condition) + earthquake.

II. Parameter values

The parameters of slip band soil are valued based on the test values of this test and the empirical values in the region. The average natural weight is set as $19.73 \mathrm{kN} / \mathrm{m}^{3}$ and the saturated weight is set as $20.4 \mathrm{kN} / \mathrm{m}^{3}$.

The soft and thin slip band soil in Guanlingping landslide area contains a lot of gravels. It is easily damaged during drilling. Taking account of the significant deformation signs and features of the area, the author obtains the cohesion $\mathrm{c}$ and internal friction angle $\varphi$ of slip band soil through landslide inversion and verifies the values with the slip band soil exposed in drilling. Combined with the regional empirical values, the natural shear strength (cohesion c: $9.70 \mathrm{kPa}$; internal friction angle $\varphi: 12.20^{\circ}$ ) and saturated strength (cohesion c: $8.82 \mathrm{kPa}$; internal friction angle $\varphi: 10.95^{\circ}$ ) are finalized.

The designed safety factor $\left(K_{s}\right)$ of thrust calculation is valued in light of the grade and condition of the landslide control project (Grade III) and in accordance with the Specification of Design and Construction of Landslide Stabilization. The $K_{s}$ is $1.15,1.10$ and 1.05 for Condition I, Condition II and Condition III, respectively.

See Table 1 for the results of landslide stability and thrust calculation.

\subsubsection{Results of landslide stability calculation}

See Table 1 for the results of landslide stability and thrust calculation.

In reference to the Table of Landslide Stability Coefficients (Table 2) in the Specification of Design and Construction of Landslide Stabilization and in light of the results of landslide stability and thrust calculation, the comprehensive evaluation results of landslide stability and landslide thrust are as below:

The landslide mass is basically stable in natural condition, basically unstable in heavy rains and basically stable in 
Table 1. Results of landslide stability calculation

\begin{tabular}{cccccc}
\hline $\begin{array}{c}\text { Section } \\
\text { No. }\end{array}$ & Condition & $\begin{array}{c}\text { Stability } \\
\text { coefficient }\end{array}$ & Stability evaluation & $\begin{array}{c}\text { Safety } \\
\text { factor }\end{array}$ & $\begin{array}{c}\text { Sliding force of the } \\
\text { last slip band } \\
(\mathrm{KN} / \mathrm{m})\end{array}$ \\
\hline $1-1^{\prime}$ & $\begin{array}{c}\text { Dead load (natural } \\
\text { condition) }\end{array}$ & 1.144 & Basically stable & 1.15 & 37.25 \\
\hline $1-1^{\prime}$ & Dead load (heavy rain) & 1.020 & Basically unstable & 1.10 & 238.04 \\
\hline $1-1^{\prime}$ & $\begin{array}{c}\text { Dead load (natural } \\
\text { condition) + earthquake }\end{array}$ & 1.089 & Basically stable & 1.05 & 0 \\
\hline $2-2^{\prime}$ & $\begin{array}{c}\text { Dead load (natural } \\
\text { condition) }\end{array}$ & 1.138 & Basically stable & 1.15 & 40 \\
\hline $2-2^{\prime}$ & Dead load (heavy rain) & 1.012 & Basically unstable & 1.10 & 313.32 \\
\hline $2-2^{\prime}$ & $\begin{array}{c}\text { Dead load (natural } \\
\text { condition) + earthquake }\end{array}$ & 1.079 & Basically stable & 1.05 & 0 \\
\hline $3-3^{\prime}$ & $\begin{array}{c}\text { Dead load (natural } \\
\text { condition) }\end{array}$ & 1.141 & Basically stable & 1.15 & 21.17 \\
\hline $3-3^{\prime}$ & Dead load (heavy rain) & 1.018 & Basically unstable & 1.10 & 220.13 \\
\hline $3-3^{\prime}$ & $\begin{array}{c}\text { Dead load (natural } \\
\text { condition) + earthquake }\end{array}$ & 1.081 & Basically stable & 1.05 & 0 \\
\hline
\end{tabular}

Table 2. Grading of landslide stability status

\begin{tabular}{|c|c|c|c|c|}
\hline $\begin{array}{c}\text { Landslide stability } \\
\text { coefficient }\end{array}$ & $K_{f}<1.00$ & $1.00 \leq K_{f}<1.05$ & $1.05 \leq K_{f}<1.15$ & $K_{f} \geq 1.15$ \\
\hline Stability status & Unstable & Basically unstable & Basically stable & Stable \\
\hline
\end{tabular}

\section{CONCLUSIONS}

(1) In the shape of a round-backed armchair, the Guanlinping landslide area in Longqiao Village, Xin'an Town has a total earth volume of $24.36 \times 106 \mathrm{~m} 3$. The main sliding direction is $272^{\circ}$. In terms of scale, it a medium-sized thrust load-induced shallow soil landslide area.

(2) The landslide develops in stratums of Quaternary colluvial deposits (Q4dl+col) and landslide deposits (Q4del); the landslide mass is predominantly made of the Upper Triassic Xujiahe Formation (T3xj) sandstones; the strike and dip of the outcropping bedrock of the slope is $275^{\circ} \angle 9^{\circ}$, which is consistent with the sliding direction. Thus, the research object is a consequent landslide area.

(3) The landslide mass is basically stable in natural condition, basically unstable in heavy rains and basically stable in earthquakes.

\section{REFERENCES}

[1] Xue T., Wang Z.H. (2017). Analysis of a landslide mechanism and its stability evaluation based on subsurface displacement monitoring, The Chinese Journal of Geological Hazard and Control, No. 4, pp. 53-61.

[2] Sun J.L. (2017). Landslide analysis and control measure in Sandaoling Open-pit Mine, Opencast Mining Technology, No. 2, pp. 21-26.

[3] Liu H.D. (2017). Landslide stability analysis of certain railway and study of control measures, Subgrade Engineering, No. 1, pp. 213-217.

[4] Lu H.Q., Zhou J.H. (2017). Basic characteristics and formation mechanism of bedding landslide in Hillyand Mountainous Areas of Yinxi, Bulletin of Science and Technology, No. 2, pp. 34-38.
[5] Kumar M., Rana S., Pant P.D., Patel R.C. (2017). Slope stability analysis of Balia Nala landslide, Kumaun Lesser Himalaya, Nainital, Uttarakhand, India, Journal of Rock Mechanics and Geotechnical Engineering, Vol. 01, pp. 150-158.

[6] Montrasio L. (2016). Modelling rainfall-induced shallow landslides at different scales using SLIP - Part II, Procedia Engineering, Vol.158, pp. 482-486.

[7] Bovenga F., Pasquariello G., Pellicani R., Refice A., Spilotro G. (2016). Landslide monitoring for risk mitigation by using corner reflector and satellite SAR interferometry: the large landslide of Carlantino (Italy), Catena, Vol.151, pp. 49-62.

[8] Zydroń T., Bucała A., Demczuk P. (2016). Analysis of rainfall-induced shallow landslides in Jamne and Jaszcze stream valleys (Polish Carpathians) preliminary results, Annals of Warsaw University of Life Sciences - SGGW. Land Reclamation, Vol. 48, No. 1, pp. 27-40.

[9] He K., Chen C.L. (2014). Stability analysis of Puzi Landslide in Chongqing, Applied Mechanics and Materials, Vol. 3307, pp. 923-926.

[10] Wang H.L., Xu W.Y. (2013). Stability of Liangshuijing landslide under variation water levels of Three Gorges Reservoir, European Journal of Environmental and Civil Engineering, Vol. 17, No. sup1, pp. S158-S173.

[11] Marek R., Hrubešová E., Sedláček M. (2011). The analysis of slope stability of the stream Výšina in Orlová, Transactions of the VŠB - Technical University of Ostrava. Construction Series, Vol. 11, No. 1, pp. 1-7.

[12] Morrissey M.M., Wieczorek G.F., Morgan B.A. (2008). A comparative analysis of simulated and observed landslide locations triggered by Hurricane 
Camille in Nelson County, Virginia, Hydrol. Process, Vol. 22, No. 4, pp. 524-531.

[13] Jašarević I., Lebo Ž. (2000). Analysis of Husino landslide in Tuzla and improvement possibilities, Građevinar, Vol. 52, No. 01, pp. 17-23.

[14] Fernández C.I., Castillo T.F.D., Hamdouni R.E., Montero J.C. (1999). Verification of landslide susceptibility mapping: a case study, Earth Surf. Process. Landforms, Vol. 24, No. 6, pp. 537-544.

[15] Specification of geological investigation for landslide stabilization (2006). DZ/T0218, China.

[16] Specification of design and construction for landslide stabilization (2006). DZ/T0219, China. 